DOI: https://doi.org/10.47405/mjssh.v5i6.432

\begin{tabular}{|c|c|}
\hline 4 & Malaysian Journal of Social Sciences and Humanities (MJSSH) \\
\hline $\begin{array}{l}\text { Malaysian Journal of } \\
\text { Social sciences and }\end{array}$ & Volume 5, Issue 6, June 2020 \\
\hline (MJ-SSH) & e-ISSN : 2504-8562 \\
\hline & $\begin{array}{l}\text { Journal home page: } \\
\text { www.msocialsciences.com }\end{array}$ \\
\hline
\end{tabular}

\title{
Kewangan, Jaringan Institusi dan Teknologi Pendorong Tingkah Laku Inovasi Pembungkusan Usahawan Mikro
}

\author{
Mahani Amat' ${ }^{1}$, Suraiya Ishak ${ }^{1}$ \\ ${ }^{1}$ Pusat Pembangunan, Sosial dan Persekitaran, Fakulti Sains Sosial dan Kemanusiaan, \\ Universiti Kebangsaan Malaysia (UKM)
}

Correspondence: Mahani Amat (mahanihalimi@gmail.com.my)

\begin{abstract}
Abstrak
Tingkah laku inovasi pembungkusan disokong oleh faktor yang mendorong tingkah laku yang terdiri daripada faktor kewangan, jaringan institusi dan teknologi. Artikel ini bertujuan untuk mengukur tahap faktor pendorong tingkah laku inovasi pembungkusan yang terdiri daripada kepentingan kewangan, jaringan institusi dan teknologi. Kerangka kajian ini dibina berasaskan kepada Teori Tingkah Laku Terancang. Seramai 40 orang usahawan mikro makanan di negeri Selangor telah dipilih sebagai sampel kajian melalui teknik persampelan rawak sistematik. Instrumen kajian ini terdiri daripada soal selidik dengan enam skala Likert dan mengandungi item-item yang telah disahkan oleh pakar-pakar penilai serta mempunyai nilai kebolehpercayaan yang baik. Data kajian ini dianalisis secara statistik deskriptif iaitu berasaskan nilai min dan peratusan. Dapatan kajian menunjukkan secara keseluruhan purata peratusan dan nilai min bagi tahap kepentingan kewangan, jaringan institusi dan teknologi mengenai tingkah laku inovasi pembungkusan adalah tinggi. Kesimpulannya, tingkah laku inovasi pembungkusan dalam kalangan usahawan mikro perlu disokong oleh faktor kewangan, jaringan institusi dan teknologi daripada agensi sokongan.
\end{abstract}

Kata kunci: kewangan, jaringan institusi, teknologi, inovasi pembungkusan, usahawan mikro

\section{Financial, Instituitional Networking and Technology Driven Micro Entrepreneurs Packaging Innovation Behavior}

\begin{abstract}
Packaging innovation behavior are influenced by financial, instituitional networking and technology factors. This article aims to measure the importance of financial, instituitional networking and technology factors in packaging innovation behavior. The framework of this study is based on Theory of Planned Behaviour, where 40 micro entrepreneurs in Selangor food industry were taken as the sample of the study based on simple random sampling techniques. A six-Likert-scale questionnaire was used as the research instrument that consists of items verified by the experts of the subject. The data were analysed using descriptive statistics that is based on mean value and percentage. The findings showed that, the average percentages and the mean values for financial, instituitional networking and technology are considered as important factors in packaging innovation behavior since the overall score is high. In conclusion, packaging innovation behavior among micro entrepreneurs should be supported by the financial, instituitional networking and technology factors from the supporting agencies.
\end{abstract}


DOI: https://doi.org/10.47405/mjssh.v5i6.432

Keywords: financial, instituitional networking, technology, packaging innovation, micro enterpreneurs

\section{Pengenalan}

Perusahaan kecil dan sederhana (PKS) telah memberikan sumbangan penting dalam pertumbuhan ekonomi dan meningkatkan pendapatan. Pertumbuhan pekerjaan juga dipacu oleh PKS, tetapi PKS memerlukan pelaburan yang lebih tinggi untuk meningkatkan upah dan produktiviti dalam kemahiran, inovasi dan teknologi (OECD, 2019). Majoriti perniagaan di semua negara di dunia adalah perniagaan berskala mikro antara 70\% hingga 95\% (OECD 2018). Di Malaysia pula, perniagaan mikro telah menyumbangkan sebanyak 76.5\% dalam pertumbuhan ekonomi negara (SME Corp. Malaysia, 2018). Melihat akan kepentingan sumbangan usahawan mikro, terdapat lebih 60 buah agensi kerajaan di Malaysia dipertanggungjawabkan untuk membantu, memfokuskan dan membangunkan usahawan mikro (SME Corp. Malaysia, 2018). Antara khidmat agensi pembimbing yang diberikan adalah pembiayaan, bantuan peralatan, perkongsian teknologi, khidmat nasihat dan jaringan perniagaan. Tujuannya bagi memastikan usahawan mikro terus dapat berdaya saing dalam pasaran yang semakin kompetitif.

Bagi memastikan usahawan mikro terus kekal relevan dalam pasaran, produk yang diketengahkan haruslah mempunyai potensi dan kelihatan unik untuk dikembangkan. Pada masa ini, terdapat 1,169 atau $20 \%$ sahaja produk PKS yang telah berjaya dipasarkan di pasaraya berbanding $30 \%$ yang diperuntukkan (Anon, 2018a). Malah, Penarafan Daya Saing Perusahaan Mikro untuk Peningkatan (M-CORE) menunjukkan perusahaan mikro tergolong dalam kategori Tahap 2 adalah sebanyak $72.6 \%$ (SME Corp. Malaysia, 2018). Peratusan ini menunjukkan perusahaan mikro berpeluang untuk memasarkan produk ke pasaraya jika berupaya meningkatkan kualiti produk. Kreativiti dan idea untuk menghasilkan pembungkusan produk yang menarik dan berinovasi akan meningkatkan nilai produk dalam pemasaran.

Secara umumnya, pembungkusan berfungsi untuk melindungi produk daripada kesan akibat tindakan bahan kimia dan kerosakan fizikal. Pembungkusan juga berperanan penting dalam pemasaran sebagai alat komunikasi untuk mempengaruhi keputusan pembelian pengguna (Khan et al., 2017). Malah, hasil kajian menunjukkan penggunaan pembungkusan mesra alam dan reka bentuk pembungkusan seperti grafik, warna, dan informasi produk adalah penting untuk tujuan promosi dan mempengaruhi tingkah laku beli pengguna (Mohebbi, 2014; Polyakova, 2013; Shahrin et al., 2016). Kajian literatur jelas menunjukkan untuk meningkatkan pasaran produk, penampilan imej pembungkusan perlu ditambah baik.

Namun, pembungkusan produk usahawan PKS khususnya berskala mikro telah menunjukkan kelemahan paling ketara seperti pembungkusan yang kurang berinovasi, tidak mempunyai imej yang menarik, penggunaan bahan pembungkus dan kaedah pembungkusan yang kurang sesuai (Ahmad Zaki, 2011; Anon, 2018b; Hutahayan \& Yufra, 2019). Malah, usahawan mikro beranggapan bahawa pembungkusan produk adalah tidak relevan dan sering kali mengabaikan kos pembungkusan dalam operasi perniagaan (Mahani \& Suraiya, 2020; Vivine, 2018). Hal ini menyebabkan pemasaran produk terkesan untuk dipasarkan. Bagi memastikan produk usahawan mikro terus dapat bersaing, inovasi pembungkusan produk perlu dipertingkatkan dan disokong oleh faktor kewangan, teknologi, dan jaringan institusi untuk merealisasikan idea inovasi pembungkusan.

Kajian lepas menunjukkan tingkah laku inovasi usahawan mikro didorong oleh tingkah laku persekitaran kerja, kewangan, sokongan teknikal, jaringan institusi, pengetahuan, dan teknologi (Alhosseini et al., 2015; Handayani et al., 2018; Mohd Nor Hakimin et al., 2018; Noorazah \& Juhana, 2013; Nor Asiah et al., 2016; Phuangrod et al., 2017). Sokongan kewangan, jaringan institusi, dan teknologi pembungkusan yang disediakan oleh agensi pembimbing dilihat dapat membantu meningkatkan inovasi pembungkusan. Persoalannya, apakah tahap faktor pendorong tingkah laku 
inovasi pembungkusan yang terdiri daripada kepentingan kewangan, jaringan institusi dan teknologi dalam kalangan usahawan mikro?

Justeru itu, kajian ini bertujuan untuk mengukur tahap faktor pendorong tingkah laku inovasi pembungkusan yang terdiri daripada kepentingan kewangan, jaringan institusi dan teknologi dalam kalangan usahawan mikro. Dapatan kajian ini secara tidak langsung dapat membuktikan bahawa pentingnya sokongan agensi dalam aspek kewangan, jaringan institusi dan teknologi untuk mendorong tingkah laku inovasi pembungkusan. Malah, kajian ini juga dapat memberikan manfaat kepada agensi pembimbing dalam merencanakan program pembangunan usahawan dan memfokuskan program inovasi pembungkusan pada masa akan datang.

\section{Sorotan Literatur}

Inovasi pembungkusan yang terhasil dapat membezakan produk sendiri dengan produk pesaing dan menyumbang kepada penciptaan nilai terhadap sesuatu produk (Che Mohd Zulkifli \& Anas, 2014; Rundh, 2016). Malah, penjajaran pembungkusan seperti unsur visual, warna, reka grafik, fon, saiz, bentuk dan bahan pembungkusan memberi kesan terhadap tingkah laku pembelian pengguna (Bettels et al., 2020; Lo et al., 2017; Mohamed et al., 2018). Sebagai contoh, pembungkusan visual yang lebih ceria memberikan keseronokan dan reaksi yang lebih positif oleh kanak-kanak berbanding pembungkusan biasa (Dial \& Musher-Eizenman 2020). Pihak pasar raya juga menekankan penampilan pembungkusan semasa peringkat penilaian produk walaupun sebagai sampel (Anwar, 2018). Justeru itu, kepentingan inovasi pembungkusan sebagai medium untuk meningkatkan pemasaran produk dan meningkatkan daya membeli pengguna adalah jelas. Inovasi pembungkusan berupaya ditingkatkan dengan adanya sokongan daripada agensi pembimbing yang berkaitan.

Agensi pembimbing berperanan penting untuk membantu usahawan terutamanya usahawan mikro bagi meningkatkan perniagaan. Lazimnya, bentuk perkhidmatan yang ditawarkan adalah khidmat nasihat dan jaringan perniagaan, geran pembiayaan, latihan dan perkongsian teknologi. Malah, beberapa kajian lepas turut menyatakan bahawa faktor sokongan agensi daripada aspek kewangan, jaringan institusi dan teknologi mendorong kejayaan perniagaan dan peningkatan prestasi perniagaan (Azmi et al., 2012; Maisarah \& Sarmila, 2017; Muhammad Asri \& Zaimah, 2012). Kewangan adalah faktor yang sangat kritikal untuk mempengaruhi kejayaan sesebuah perniagaan dalam melaksanakan inovasi pembungkusan (Adigun, 2016; Chittithaworn et al., 2011; Diana-Rose et al., 2016; Nor Ghani et al., 2016; Yahaya et al., 2018). Sebaliknya, terdapat kajian menyatakan inovasi tidak sinonim dengan pelaburan kewangan (Felipe \& Márcia, 2018). Hal ini kerana inovasi boleh dilaksanakan sekiranya usahawan mampu merancang sumber, menyusun semula, meningkatkan jaringan institusi dan bertindak mengikut perancangan.

Kolaborasi usahawan mikro dengan kepelbagaian sektor industri dan keupayaan melakukan jaringan institusi menunjukkan kesan yang positif dalam meningkatkan inovasi pembungkusan (Ueasangkomsate \& Jangkot, 2019). Jaringan institusi dilihat dapat membangunkan sikap, kemahiran dan pengetahuan usahawan terhadap inovasi pembungkusan (Mohd Shaladdin et al., 2011). Selain itu, jaringan institusi menjadi tempat rujukan dan menemukan usahawan dengan pelbagai pihak melalui program 'Business Matching' (Abbasi et al., 2017; Olcay \& Bulu, 2015; Ombi et al., 2018). Oleh itu, bagi memantapkan tingkah laku inovasi pembungkusan, pengukuhan hubungan antara perniagaan dan kerjasama agensi kerajaan, agensi swasta serta universiti penyelidikan dapat meningkatkan pengetahuan inovasi pembungkusan dengan lebih berkesan (Pham \& Matsunaga, 2019; Powell, 2012). Hubungan baik antara usahawan dengan institusi penyelidikan memberikan manfaat dalam perkongsian teknologi.

Teknologi bukan sekadar alat ataupun mesin, tetapi turut merangkumi teknik, kemahiran, kaedah dan proses yang digunakan untuk menyelesaikan masalah sebenar (Andersson et al., 2016; Suwardi Afandi et al., 2016). Perkembangan teknologi yang bergerak pantas telah menunjukkan peningkatan penambahbaikan dalam penggunaan bahan pembungkus, kaedah pembungkusan dan hayat simpanan (Sharina et al., 2013). Tahap teknologi usahawan mikro makanan adalah rendah kerana operasi 
pengeluaran yang minima (Zaini et al., 2004). Malah, penggunaan teknologi sedikit mundur disebabkan tahap kesedaran yang rendah dan mentaliti usahawan yang bersikap sedikit negatif terhadap teknologi (Azilahwati et al. 2016; Chapman et al., 2000). Justeru itu, sokongan teknologi adalah amat diperlukan bagi memastikan inovasi pembungkusan yang lebih berdaya tahan dan sesuai dengan sifat makanan terhasil (Suraiya et al., 2015).

Berdasarkan kepada kajian literatur Mahani dan Suraiya (2019), faktor sikap, pengetahuan, kesedaran, kewangan, jaringan institusi dan teknologi dapat mempengaruhi tingkah laku inovasi pembungkusan dalam kalangan usahawan mikro. Justeru itu, kajian ini dijalankan adalah berlandaskan kepada Teori Tingkah Laku Terancang (Ajzen, 1991) (Rajah 1). Berdasarkan kepada Teori Tingkah Laku Terancang, tingkah laku seseorang dipengaruhi oleh faktor sikap, norma subjektif dan kawalan perilaku berlaku dalam keadaan sedar setelah mempertimbangkan segala informasi yang tersedia. Oleh itu, terdapat ruang untuk mengukur tahap kepentingan kewangan, jaringan institusi dan teknologi yang mendorong tingkah laku inovasi pembungkusan untuk dikaji.

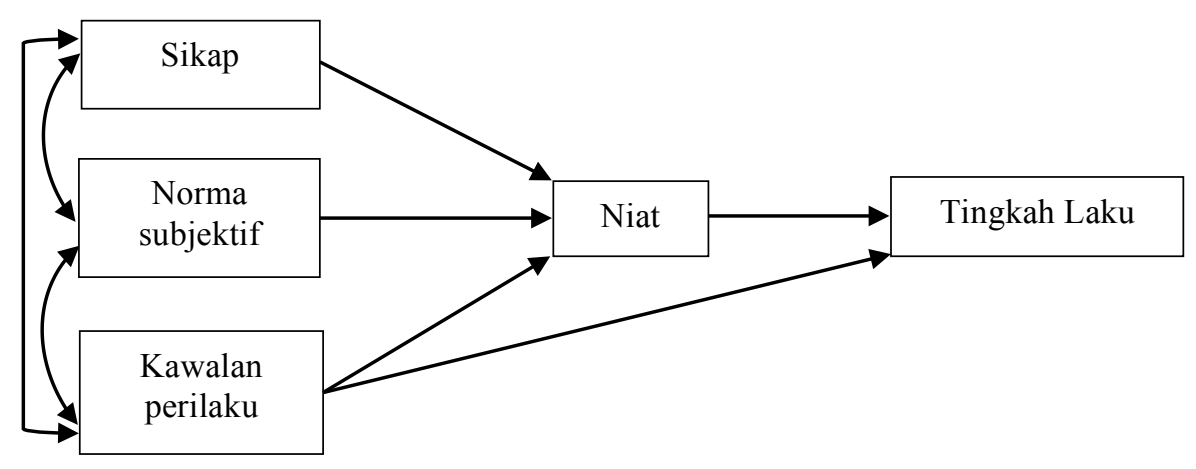

Rajah 1: Teori Tingkah Laku Terancang (Ajzen 1991)

\section{Metod Kajian}

Kajian ini telah dilakukan secara tinjauan. Instrumen soal selidik digunakan untuk tujuan pengumpulan data yang dibahagikan kepada 4 bahagian iaitu bahagian demografi, pengukuran aspek kewangan, jaringan institusi dan teknologi. Pengukuran pemboleh ubah tahap kepentingan kewangan, jaringan institusi dan teknologi telah dilakukan menggunkan skala Likert 6 mata terdiri daripada (1) sangat tidak setuju sehingga (6) sangat setuju. Item pernyataan terdiri daripada soal selidik yang diubahsuai berdasarkan kajian-kajian lepas selaras dengan objektif kajian. Instrumen ini telah disahkan oleh 4 orang pakar penilai dalam bidang keusahawanan dan perniagaan, teknologi pembungkusan makanan, dan pembangunan sumber manusia dan penilaian latihan, 2 orang pegawai agensi di agensi pembimbing dan 2 orang usahawan dalam bidang perusahaan makanan. Nilai kebolehpercayaan Cronbach's Alpha seperti dalam Jadual 1. Menurut Hair et al. (2007) nilai Cronbach's Alpha yang melebihi 0.7 dikategorikan sebagai item yang mempunyai kebolehpercayaan yang baik.

Jadual 1: Nilai kebolehpercayaan Cronbach's Alpha

\begin{tabular}{lccc}
\hline \multicolumn{1}{c}{ Pemboleh ubah } & $\begin{array}{c}\text { Cronbach's } \\
\text { Alpha }\end{array}$ & Bilangan Item & Konsistensi Dalaman \\
\hline Kewangan & 0.640 & 7 & Sederhana \\
Jaringan Institusi & 0.861 & 9 & Sangat Baik \\
Teknologi & 0.955 & 6 & Cemerlang \\
\hline
\end{tabular}

Kajian ini telah dijalankan di negeri Selangor dan sampel kajian melibatkan 40 orang usahawan mikro makanan yang telah mendapat bimbingan pembungkusan daripada agensi seperti Jabatan Pertanian, MARDI, FAMA dan UPEN Selangor. Justifikasi pemilihan agensi berdasarkan kepada peranan aktif agensi untuk penambahbaikan pembungkusan produk makanan usahawan mikro. Kaedah pensampelan 
menggunakan teknik pensampelan rawak sistematik bagi mengelakkan bias. Data kajian diperoleh melalui edaran borang soal selidik kepada usahawan secara pertemuan bersemuka, melalui pos dan pengisian secara maya menggunakan google dokumen. Bagi meningkatkan maklum balas, usahawan dihubungi dan diberikan peringatan mesra berulang kali serta diberikan e-book berkaitan pemasaran kepada usahawan yang telah memberikan maklum balas. Dalam kajian ini, analisis deskriptif digunakan bagi menjawab objektif kajian. Tahap kepentingan kewangan, jaringan institusi dan teknologi yang dikaji adalah menggunakan peratusan dan min seterusnya analisis tahap interpretasi diambil kira daripada nilai enam mata. Jadual 2 menunjukkan interpretasi min yang digunakan dalam dapatan kajian bagi pengukuran faktor kewangan, jaringan institusi dan teknologi.

Jadual 2: Interpretasi min bagi kewangan, jaringan institusi dan teknologi

\begin{tabular}{cc}
\hline Julat Min & Interpretasi \\
\hline $0.00-2.49$ & Rendah \\
$2.50-4.49$ & Sederhana \\
$4.50-6.00$ & Tinggi \\
\hline
\end{tabular}

Sumber: Jeff Pruchnic et al. (2018)

\section{Dapatan Kajian dan Perbincangan}

\section{Kewangan}

Jadual 3 menunjukkan analisis kepentingan kewangan bagi setiap item kewangan untuk menyokong inovasi pembungkusan usahawan mikro. Hasil dapatan kajian menunjukkan kesemua tujuh item tersebut mempunyai skor min yang tinggi. Item yang mempunyai skor yang tertinggi adalah bantuan kewangan penting untuk melakukan aktiviti inovasi pembungkusan $(\min =5.75)$ dengan jumlah peratus responden setuju $25.0 \%$ dan sangat setuju adalah sebanyak $75.0 \%$. Diikuti dengan peruntukan kewangan yang mencukupi perlu untuk aktiviti inovasi pembungkusan $(\min =5.65)$ dengan jumlah peratus responden yang setuju dan sangat setuju adalah sebanyak $35.0 \%$ dan $65 \%$. Manakala, saya sentiasa berusaha mendapatkan info bantuan pembiayaan untuk inovasi pembungkusan $(\min =5.65)$ dengan jumlah peratus responden yang setuju $35.0 \%$ dan sangat setuju adalah sebanyak $65.0 \%$. Item bagi kewangan mempengaruhi inovasi pembungkusan $(\min =5.60)$ pula menunjukkan setuju dan sangat setuju adalah sebanyak $95 \%$ dan sedikit setuju $5.0 \%$. Seterusnya, item dengan halangan kewangan, saya tidak boleh melakukan inovasi pembungkusan $(\min =5.20)$ menunjukkan pecahan yang berbeza iaitu setuju $27.5 \%$, sangat setuju adalah sebanyak $55 \%$, sedikit setuju $10 \%$ dan sangat tidak setuju 2.5\%. Manakala, item saya berupaya untuk mendapatkan sumber kewangan bagi membolehkan aktiviti inovasi pembungkusan dilakukan $(\min =5.13)$ setuju dan sangat setuju adalah sebanyak $77.5 \%$, sedikit setuju $15 \%$ dan kurang setuju $7.5 \%$. Item yang memberikan min terendah adalah saya menyediakan peruntukan kewangan untuk inovasi pembungkusan $(\min =5.13)$ setuju $37.5 \%$, sangat setuju adalah sebanyak $37.5 \%$, dan sedikit setuju $25 \%$. Secara keseluruhannya, skor kepentingan kewangan untuk menyokong inovasi pembungkusan adalah tinggi $(\mathrm{min}=5.44)$ dengan jumlah purata peratus bagi responden yang sangat setuju dan setuju adalah $90.7 \%$, hanya $6.4 \%$ yang sedikit setuju, $2.5 \%$ kurang setuju dan $0.4 \%$ sangat tidak setuju.

Jadual 3: Analisis tahap kepentingan kewangan bagi setiap pernyataan

\begin{tabular}{|c|c|c|c|c|c|c|c|c|}
\hline No & Pernyataan & $\begin{array}{l}\text { STS } \\
(\%)\end{array}$ & $\begin{array}{l}\text { TS } \\
(\%)\end{array}$ & $\begin{array}{l}\text { KS } \\
(\%)\end{array}$ & $\begin{array}{l}\mathrm{SeS} \\
(\%)\end{array}$ & $\begin{array}{c}\mathrm{S} \\
(\%)\end{array}$ & $\begin{array}{c}\text { SS } \\
(\%)\end{array}$ & Min \\
\hline 1 & $\begin{array}{l}\text { Kewangan mempengaruhi inovasi } \\
\text { pembungkusan. }\end{array}$ & 0.0 & $\begin{array}{l}0 . \\
0\end{array}$ & 0.0 & 5.0 & $\begin{array}{c}30 . \\
0\end{array}$ & 65.0 & 5.60 \\
\hline 2 & $\begin{array}{l}\text { Bantuan kewangan penting untuk } \\
\text { melakukan aktiviti inovasi } \\
\text { pembungkusan. }\end{array}$ & 0.0 & $\begin{array}{l}0 . \\
0\end{array}$ & 0.0 & 0.0 & $\begin{array}{c}25 . \\
0\end{array}$ & 75.0 & 5.75 \\
\hline 3 & Peruntukan kewangan yang mencukupi & 0.0 & 0 . & 0.0 & 0.0 & 35. & 65.0 & 5.65 \\
\hline
\end{tabular}


Malaysian Journal of Social Sciences and Humanities (MJSSH), Volume 5, Issue 6, (page 79 - 90), 2020

DOI: https://doi.org/10.47405/mjssh.v5i6.432

perlu untuk aktiviti inovasi

pembungkusan.

4 Saya sentiasa berusaha mendapatkan info bantuan pembiayaan untuk inovasi pembungkusan.

5 Saya berupaya untuk mendapatkan sumber kewangan bagi membolehkan aktiviti inovasi pembungkusan dilakukan.

6 Saya menyediakan peruntukan kewangan untuk inovasi pembungkusan.

7 Dengan halangan kewangan, saya tidak boleh melakukan inovasi pembungkusan.

\begin{tabular}{ccccccc}
0.0 & 0. & 0.0 & 0.0 & 35.0 & 65.0 & 5.65 \\
& 0 & & & & & \\
0.0 & 0. & 7.5 & 15. & 35. & 42.5 & 5.13 \\
& 0 & & 0 & 0 & & \\
& & & & & & \\
0.0 & 0. & 0.0 & 25. & 37. & 37.5 & 5.13 \\
& 0 & & 0 & 5 & & \\
& & & & & & \\
2.5 & 0. & 10. & 5.0 & 27. & 55.0 & 5.20 \\
& 0 & 0 & & 5 & & \\
& & & & & & \\
\hline 0.4 & 0. & 2.5 & 6.4 & 27. & 62.8 & 5.44 \\
& 0 & & & 9 & & \\
\hline
\end{tabular}
Keseluruhan

Nota: STS - Sangat tidak setuju, TS - Tidak setuju, KS - Kurang setuju, SeS - Sedikit setuju, S Setuju, SS - Sangat setuju

Penemuan ini menunjukkan bahawa tahap kepentingan kewangan adalah tinggi dalam kalangan usahawan mikro untuk melaksanakan inovasi pembungkusan. Faktor kewangan sangat penting dalam perniagaan terutamanya yang berskala mikro terutamanya untuk mendorong tingkah laku inovasi pembungkusan. Usahawan mikro yang mempunyai sumber kewangan yang kukuh mampu meningkatkan keupayaan tingkah laku inovasi pembungkusan. Malahan, usahawan mikro memerlukan sokongan agensi dari aspek bantuan dan peruntukkan kewangan bagi menyokong inovasi pembungkusan itu berlaku. Alasan ini selari dengan kajian lepas oleh Olcay dan Bulu (2015) dan Vasilescu (2014) yang menyatakan inovasi pembungkusan sukar dilaksanakan oleh usahawan berskala kecil dan mikro tanpa sokongan sumber kewangan yang baik dan dana yang mencukupi. Selain itu, usahawan mikro juga senantiasa berusaha bagi mendapatkan informasi berkaitan pembiayaan daripada agensi yang berkaitan. Dapatan ini turut disokong oleh penemuan kajian Norkisme et al. (2017) yang turut mendapati bahawa daya usaha yang ditunjukkan oleh usahawan mikro untuk mendapatkan bantuan dan peruntukkan daripada agensi sokongan berupaya merealisasikan idea inovasi. Penemuan ini bertentangan dengan kajian Felipe dan Márcia (2018) yang menyatakan inovasi tidak sinonim dengan pelaburan kewangan.

Walau bagaimanapun, dapatan kajian juga menunjukkan usahawan mikro masih kurang berupaya untuk mendapatkan sumber kewangan daripada agensi sokongan bagi membolehkan aktiviti inovasi pembungkusan dilakukan. Hal ini mungkin disebabkan kemampuan usahawan mikro untuk memenuhi syarat pembiayaan dan kesukaran menyediakan dokumen sokongan menyebabkan kekangan untuk mendapatkan sumber pembiayaan daripada agensi. Tambahan lagi, informasi berkaitan pembiayaan juga kurang mencukupi. Alasan ini juga selari dengan dapatan kajian oleh Hyder dan Lussier (2016); dan Rossi dan Siggia (2015) yang menyatakan usahawan mikro perlu menyediakan dokumen kewangan yang lengkap dan perlu mempunyai keupayaan untuk mengakses maklumat berkaitan pembiayaan. Hasil kajian ini juga menunjukkan bahawa usahawan mikro kurang menyediakan peruntukan kewangan untuk tujuan inovasi pembungkusan. Senario ini berbeza dengan usahawan di negara lain seperti Amerika Syarikat yang telah menetapkan hampir separuh perbelanjaan diperuntukan untuk tujuan pembungkusan produk (Anon, 2018c). Justeru itu, usahawan mikro seharusnya melakukan satu anjakan paradigma dengan menetapkan sejumlah peruntukan khas untuk tingkah laku inovasi pembungkusan bagi melonjakkan produk di pasaran. Hal ini bagi memastikan aktiviti inovasi pembungkusan tidak terhalang di tengah jalan disebabkan kekurangan sumber sokongan kewangan. 


\section{Jaringan Institusi}

Jadual 4 menunjukkan skor min dan peratusan bagi setiap item kepentingan jaringan institusi untuk menyokong inovasi pembungkusan yang diukur oleh sembilan item. Kesemua sembilan item tersebut mempunyai skor yang tinggi. Item yang mempunyai skor yang tertinggi adalah jaringan institusi penting bagi menyokong inovasi pembungkusan $(\mathrm{min}=5.60)$ dengan jumlah peratus responden setuju $40 \%$ dan sangat setuju adalah sebanyak $60 \%$. Diikuti dengan hubungan baik dengan agensi pembimbing adalah penting untuk mendapat manfaat berkaitan inovasi pembungkusan $(\min =5.52)$ dengan jumlah peratus responden setuju dan sangat setuju adalah sebanyak $97.5 \%$ dan sedikit setuju $2.5 \%$. Manakala, item bagi saya perlukan mentor untuk membimbing dalam inovasi pembungkusan $(\min =5.50)$ pula, jumlah peratus responden setuju dan sangat setuju adalah sebanyak $95 \%$ dan sedikit setuju 5\%. Item agensi pembimbing memberikan idea-idea praktikal kepada saya untuk meningkatkan inovasi pembungkusan $(\min =5.38)$ menunjukkan jumlah peratus responden setuju dan sangat setuju adalah sebanyak $92.5 \%$ dan sedikit setuju $7.5 \%$. Seterusnya, agensi pembimbing menemukan saya dengan pihak-pihak yang membantu saya melakukan inovasi pembungkusan (Business Matching) $(\min =5.37)$ dengan jumlah peratus responden setuju dan sangat setuju adalah sebanyak $97.5 \%$ dan sedikit setuju $2.5 \%$. Item agensi pembimbing adalah pusat rujukan utama saya untuk melakukan inovasi dalam pembungkusan $(\mathrm{min}=5.35$ ) dengan jumlah peratus responden setuju dan sangat setuju adalah sebanyak $95.0 \%$, sedikit setuju $2.5 \%$ dan kurang setuju $2.5 \%$. Manakala, item saya berupaya berkerjasama dengan institusi lain untuk melakukan inovasi pembungkusan $(\min =5.30)$ dengan jumlah peratus responden setuju dan sangat setuju adalah sebanyak $90 \%$, sedikit setuju $7.5 \%$ dan kurang setuju $2.5 \%$. Item penting untuk melibatkan diri dalam aktiviti persatuan bagi mendapat manfaat berkaitan inovasi pembungkusan $(\min =5.30)$ pula menunjukkan jumlah peratus responden setuju dan sangat setuju adalah sebanyak $92.5 \%$ dan sedikit setuju $7.5 \%$. Min terendah adalah saya mendapat sokongan yang cukup dari agensi pembimbing untuk melakukan inovasi pembungkusan $(\min =5.08)$ dengan jumlah peratus responden setuju dan sangat setuju adalah sebanyak $77.5 \%$, sedikit setuju 20\% dan kurang setuju 2.5\%. Secara keseluruhannya, skor kepentingan jaringan institusi untuk menyokong tingkah laku inovasi pembungkusan adalah tinggi $(\min =5.38)$ dengan jumlah peratus responden setuju dan sangat setuju adalah sebanyak $92 \%$, sedikit setuju $7.2 \%$ dan kurang setuju $0.8 \%$.

Jadual 4: Analisis tahap kepentingan jaringan institusi bagi setiap pernyataan

\begin{tabular}{|c|c|c|c|c|c|c|}
\hline No & Pernyataan & $\begin{array}{l}\mathrm{KS} \\
(\%)\end{array}$ & $\begin{array}{l}\text { SeS } \\
(\%)\end{array}$ & $\begin{array}{c}\mathrm{S} \\
(\%)\end{array}$ & $\begin{array}{c}\text { SS } \\
(\%)\end{array}$ & Min \\
\hline 1 & $\begin{array}{l}\text { Jaringan institusi penting bagi menyokong inovasi } \\
\text { pembungkusan. }\end{array}$ & 0.0 & 0.0 & $\begin{array}{c}40 . \\
0\end{array}$ & $\begin{array}{c}60 . \\
0\end{array}$ & 5.60 \\
\hline 2 & $\begin{array}{l}\text { Agensi pembimbing menemukan saya dengan pihak- } \\
\text { pihak yang membantu saya melakukan inovasi } \\
\text { pembungkusan (Business Matching). }\end{array}$ & 2.5 & 2.5 & $\begin{array}{c}50 . \\
0\end{array}$ & $\begin{array}{c}45 . \\
0\end{array}$ & 5.37 \\
\hline 3 & $\begin{array}{l}\text { Agensi pembimbing memberikan idea-idea praktikal } \\
\text { kepada saya untuk meningkatkan inovasi } \\
\text { pembungkusan. }\end{array}$ & 0.0 & 7.5 & $\begin{array}{c}47 . \\
5\end{array}$ & $\begin{array}{c}45 . \\
0\end{array}$ & 5.38 \\
\hline 4 & $\begin{array}{l}\text { Agensi pembimbing adalah pusat rujukan utama saya } \\
\text { untuk melakukan inovasi dalam pembungkusan. }\end{array}$ & 0.0 & $\begin{array}{c}12 . \\
5\end{array}$ & 40.0 & $\begin{array}{c}47 . \\
5\end{array}$ & 5.35 \\
\hline 5 & $\begin{array}{l}\text { Saya mendapat sokongan yang cukup dari agensi } \\
\text { pembimbing untuk melakukan inovasi } \\
\text { pembungkusan. }\end{array}$ & 2.5 & $\begin{array}{c}20 . \\
0\end{array}$ & $\begin{array}{c}45 . \\
0\end{array}$ & $\begin{array}{c}32 . \\
5\end{array}$ & 5.08 \\
\hline 6 & $\begin{array}{l}\text { Hubungan baik dengan agensi pembimbing adalah } \\
\text { penting untuk mendapat manfaat berkaitan inovasi } \\
\text { pembungkusan. }\end{array}$ & 0.0 & 2.5 & $\begin{array}{c}42 . \\
5\end{array}$ & $\begin{array}{c}55 . \\
0\end{array}$ & 5.52 \\
\hline 7 & $\begin{array}{l}\text { Saya berupaya berkerjasama dengan institusi lain } \\
\text { untuk melakukan inovasi pembungkusan. }\end{array}$ & 2.5 & 7.5 & $\begin{array}{c}47 . \\
5\end{array}$ & $\begin{array}{c}42 . \\
5\end{array}$ & 5.30 \\
\hline 8 & $\begin{array}{l}\text { Penting untuk melibatkan diri dalam aktiviti } \\
\text { persatuan bagi mendapat manfaat berkaitan inovasi }\end{array}$ & 0.0 & 7.5 & $\begin{array}{c}55 . \\
0\end{array}$ & $\begin{array}{c}37 . \\
5\end{array}$ & 5.30 \\
\hline
\end{tabular}


pembungkusan.

\begin{tabular}{|c|c|c|c|c|c|c|}
\hline 9 & $\begin{array}{l}\text { Saya perlukan mentor untuk membimbing dalam } \\
\text { inovasi pembungkusan. }\end{array}$ & 0.0 & 5.0 & $\begin{array}{c}40 . \\
0\end{array}$ & 55.0 & 5.50 \\
\hline & Keseluruhan & 0.8 & 7.2 & $\begin{array}{c}45 . \\
3\end{array}$ & 46.7 & 5.38 \\
\hline
\end{tabular}

Nota: KS- Kurang setuju, SeS-Sedikit setuju, S-Setuju, SS-Sangat setuju

Penemuan ini menunjukkan bahawa tahap kepentingan jaringan institusi adalah tinggi dalam kalangan usahawan mikro untuk melaksanakan inovasi pembungkusan. Faktor jaringan institusi adalah penting bagi menyokong inovasi pembungkusan dalam kalangan usahawan mikro. Malah, usahawan mikro berpendapat hubungan baik usahawan mikro dengan agensi pembimbing adalah penting untuk usahawan mikro mendapat manfaat berkaitan inovasi pembungkusan. Usahawan mikro juga memerlukan khidmat sokongan mentor untuk membimbing dalam inovasi pembungkusan. Sokongan jaringan institusi bukan sekadar membangunkan diri usahawan mikro untuk meningkatkan prestasi perniagaan (Abbasi et al., 2017; Mohd Shaladdin et al., 2011; Olcay \& Bulu, 2015; Ombi et al. , 2018), tetapi juga menggalakkan tingkah laku inovasi pembungkusan terutamanya dalam kalangan usahawan mikro makanan. Jaringan institusi yang diberikan dalam bentuk bimbingan khidmat nasihat dan latihan yang berterusan daripada agensi pembimbing berupaya membentuk sikap yang positif seperti mana dalam kajian Noorsafiza (2016).

Agensi pembimbing perlu meningkatkan kualiti perkhidmatan dengan memberikan idea-idea yang lebih praktikal kepada usahawan mikro untuk meningkatkan inovasi pembungkusan. Agensi pembimbing juga perlu lebih aktif melakukan padanan perniagaan untuk tujuan meningkatkan inovasi pembungkusan. Hal ini kerana usahawan mikro menyatakan masih kurang mendapat sokongan yang cukup dari agensi pembimbing untuk melakukan inovasi pembungkusan. Bimbingan agensi yang berterusan akan memberikan kesan terhadap kesedaran usahawan mikro makanan untuk tingkah laku inovasi pembungkusan yang lebih efektif dan berkesan. Hal ini juga selari dengan beberapa kajian lepas yang menyatakan bahawa kepentingan jaringan institusi sebagai tempat rujukan dan menemukan usahawan dengan pelbagai pihak melalui program 'Business Matching' untuk mengukuhkan perniagaan (Abbasi et al., 2017; Olcay \& Bulu, 2015; Ombi et al., 2018). Malah, usahawan mikro juga perlu meningkatkan keupayaan dan aktif untuk berkerjasama dengan institusi lain untuk melakukan inovasi pembungkusan. Penglibatan usahawan mikro dalam aktiviti persatuan perlu ditingkatkan bagi mendapat manfaat daripada rakan usahawan untuk berkongsi pengetahuan dan bertukar pandangan mengenai inovasi pembungkusan. Oleh itu, bagi memantapkan tingkah laku inovasi pembungkusan, pengukuhan hubungan antara perniagaan dan kerjasama agensi kerajaan, agensi swasta serta universiti penyelidikan dapat meningkatkan pengetahuan inovasi pembungkusan dengan lebih berkesan (Pham \& Matsunaga, 2019; Powell, 2012).

\section{Teknologi}

Jadual 5 menunjukkan skor min dan peratusan bagi setiap item kepentingan teknologi untuk menyokong inovasi pembungkusan yang diukur oleh enam item. Hasil kajian menunjukkan kesemua enam item tersebut mempunyai skor yang tinggi. Item yang mempunyai skor yang tertinggi adalah bantuan peralatan dan mesin pembungkusan daripada agensi adalah perlu $(\min =5.73)$ dengan jumlah peratus responden setuju $27.5 \%$ dan sangat setuju adalah sebanyak $72.5 \%$. Diikuti dengan sokongan teknologi pembungkusan dari agensi adalah penting untuk melakukan inovasi pembungkusan $(\mathrm{min}=$ 5.68) dengan jumlah peratus responden setuju $32.5 \%$ dan sangat setuju adalah sebanyak $67.5 \%$. Item teknologi pembungkusan membantu saya untuk melakukan inovasi pembungkusan bagi meningkatkan kualiti pembungkusan produk $(\min =5.65)$ dengan jumlah peratus responden setuju $35 \%$ dan sangat setuju adalah sebanyak 65\%. Manakala, item teknologi pembungkusan membantu saya untuk melakukan inovasi pembungkusan bagi meningkatkan pasaran produk $(\min =5.63)$ dan item teknologi pembungkusan membantu saya untuk melakukan inovasi pembungkusan bagi meningkatkan produktiviti pengeluaran $(\min =5.63)$. Kedua-dua item menunjukkan jumlah peratus responden setuju $37.5 \%$ dan sangat setuju adalah sebanyak $62.5 \%$. Min terendah adalah teknologi pembungkusan membantu saya untuk melakukan inovasi pembungkusan bagi meningkatkan hayat simpanan produk 
saya $(\min =5.60)$ menunjukkan jumlah peratus responden setuju $40 \%$ dan sangat setuju adalah sebanyak $60 \%$. Secara keseluruhannya, skor kepentingan teknologi yang mendorong inovasi pembungkusan adalah tinggi $(\min =5.65)$ dengan jumlah peratus responden setuju $35 \%$ dan sangat setuju adalah sebanyak $65 \%$.

Jadual 5: Analisis tahap kepentingan teknologi bagi setiap pernyataan

\begin{tabular}{|c|c|c|c|c|c|c|}
\hline No & Pernyataan & $\begin{array}{l}\text { KS } \\
(\%)\end{array}$ & $\begin{array}{l}\text { SeS } \\
(\%)\end{array}$ & $\begin{array}{c}\mathrm{S} \\
(\%)\end{array}$ & $\begin{array}{l}\text { SS } \\
(\%)\end{array}$ & Min \\
\hline 1 & $\begin{array}{l}\text { Teknologi pembungkusan membantu saya untuk } \\
\text { melakukan inovasi pembungkusan bagi } \\
\text { meningkatkan kualiti pembungkusan produk. }\end{array}$ & 0.0 & 0.0 & 35.0 & 65.0 & 5.65 \\
\hline 2 & $\begin{array}{l}\text { Teknologi pembungkusan membantu saya untuk } \\
\text { melakukan inovasi pembungkusan bagi } \\
\text { meningkatkan pasaran produk. }\end{array}$ & 0.0 & 0.0 & 37.5 & 62.5 & 5.63 \\
\hline 3 & $\begin{array}{l}\text { Teknologi pembungkusan membantu saya untuk } \\
\text { melakukan inovasi pembungkusan bagi } \\
\text { meningkatkan hayat simpanan produk saya. }\end{array}$ & 0.0 & 0.0 & 40.0 & 60.0 & 5.60 \\
\hline 4 & $\begin{array}{l}\text { Teknologi pembungkusan membantu saya untuk } \\
\text { melakukan inovasi pembungkusan bagi } \\
\text { meningkatkan produktiviti pengeluaran. }\end{array}$ & 0.0 & 0.0 & 37.5 & 62.5 & 5.63 \\
\hline 5 & $\begin{array}{l}\text { Sokongan teknologi pembungkusan dari agensi } \\
\text { adalah penting untuk melakukan inovasi } \\
\text { pembungkusan. }\end{array}$ & 0.0 & 0.0 & 32.5 & 67.5 & 5.68 \\
\hline \multirow[t]{2}{*}{6} & $\begin{array}{l}\text { Bantuan peralatan dan mesin pembungkusan } \\
\text { daripada agensi adalah perlu. }\end{array}$ & 0.0 & 0.0 & 27.5 & 72.5 & 5.73 \\
\hline & Keseluruhan & 0.0 & 0.0 & 35.0 & 65.0 & 5.65 \\
\hline
\end{tabular}

Penemuan ini menunjukkan bahawa tahap kepentingan teknologi adalah tinggi dalam kalangan usahawan mikro untuk melaksanakan inovasi pembungkusan. Faktor teknologi adalah penting bagi mendorong inovasi pembungkusan dalam kalangan usahawan mikro. Malah, sokongan teknologi pembungkusan daripada agensi pembimbing adalah penting untuk melakukan inovasi pembungkusan. Kajian lepas turut menyatakan sokongan teknologi daripada agensi pembimbing memainkan peranan penting dalam inovasi pembungkusan sama ada dari aspek penggunaan bahan pembungkusan mahupun bantuan teknologi (Suraiya et al., 2015; Suwardi Afandi \& Mohd Arif, 2014). Dapatan kajian mendapati majoriti usahawan mikro memerlukan bantuan peralatan dan mesin pembungkusan daripada agensi pembimbing. Hal ini kerana teknologi pembungkusan dapat membantu usahawan mikro untuk melakukan inovasi pembungkusan bagi meningkatkan kualiti pembungkusan produk, meningkatkan pasaran produk, dan meningkatkan produktiviti pengeluaran. Walau bagaimanapun, agensi pembimbing perlu memberi penekanan lebih berkaitan teknologi pembungkusan untuk membantu meningkatkan hayat simpanan produk dalam kalangan usahawan mikro.

Lazimnya, tahap teknologi usahawan mikro makanan adalah rendah kerana operasi pengeluaran yang minima (Zaini et al., 2004). Malah, penggunaan teknologi sedikit mundur disebabkan tahap kesedaran yang rendah dan mentaliti usahawan yang bersikap sedikit negatif terhadap teknologi (Azilahwati et al., 2016; Chapman et al., 2000). Manakala, kekuatan hubungan teknologi ke atas tingkah laku inovasi pembungkusan pula berupaya ditingkatkan dengan adanya sokongan teknologi daripada agensi pembimbing. Teknologi yang rendah disebabkan kekangan kewangan, penghasilan produk yang kecil dan keseluruhan aktiviti pemprosesan tidak menggunakan mesin sepenuhnya (Suraiya et al., 2015; Zaini et al., 2004). Walau bagaimanapun, penemuan ini tidak boleh dianggap sebagai suatu senario yang kurang baik. Hal ini selari dengan sifat perusahaan mikro yang mengeluarkan produk secara kecil-kecilan dan pasaran yang terhad sekitar lokasi perniagaan tidak semestinya memerlukan penggunaan mesin atau teknologi yang canggih. Justeru itu, sokongan teknologi daripada agensi 
sokongan adalah amat diperlukan bagi memastikan inovasi pembungkusan dapat dilaksanakan untuk meningkatkan pasaran.

Dapatan kajian ini jelas menunjukkan bahawa faktor kewangan, jaringan institusi dan teknologi mendorong tingkah laku inovasi pembungkusan dalam kalangan usahawan mikro sebagaimana yang dikemukakan dalam Teori Tingkah Laku Terancang (Ajzen, 1991). Justeru, tingkah laku usahawan tidak mudah diubah jika hanya ada kesedaran niat semata-mata (Nasrudin et al., 2014), tetapi, tingkah laku inovasi pembungkusan boleh dilakukan dengan adanya dorongan perilaku untuk melakukan inovasi pembungkusan. Faktor kewangan, jaringan institusi dan teknologi adalah penting dalam kalangan usahawan mikro untuk melakukan inovasi pembungkusan. Manakala, agensi sokongan perlu meningkatkan kualiti perkhidmatan dan memainkan peranan lebih dalam menggalakkan inovasi pembungkusan melalui peningkatan pembiayaan, jaringan institusi dan pemindahan teknologi yang sesuai dengan keperluan semasa usahawan mikro.

\section{Kesimpulan}

Secara keseluruhan, faktor kewangan, jaringan institusi dan teknologi dapat mendorong tingkah laku inovasi pembungkusan dalam kalangan usawahan mikro dan menunjukkan tahap yang tinggi. Hal ini menunjukkan sokongan kewangan, jaringan institusi dan teknologi daripada agensi pembimbing amat diperlukan oleh usahawan mikro untuk melakukan inovasi pembungkusan. Faktor dorongan ini juga dapat membantu meningkatkan keyakinan dan menggalakkan usahawan mikro untuk melaksanakan inovasi pembungkusan seperti mana dalam Teori Tingkahlaku Terancang (TPB) (Ajzen, 1991). Teori ini meramalkan tingkah laku boleh dirancang dengan beranggapan bahawa perilaku manusia berlaku dalam keadaan yang sedar dan didorong oleh faktor dorongan perilaku. Oleh itu, usahawan mikro perlu sentiasa berusaha dan berupaya mendapatkan sokongan kewangan dan teknologi daripada agensi pembimbing. Di samping itu, usahawan mikro perlu meningkatkan jaringan institusi dengan manamana agensi pembimbing untuk mendapatkan manfaat bagi melaksanakan inovasi pembungkusan. Faktor kewangan, jaringan institusi dan teknologi ini akan memberikan impak yang lebih positif untuk penghasilan pembungkusan yang lebih berinovasi. Cadangan kajian pada masa akan datang adalah melihat hubungan faktor kewangan, jaringan institusi dan teknologi terhadap tingkah laku inovasi pembungkusan dalam kalangan usahawan mikro.

\section{Rujukan}

Abbasi, W.A., Wang, Z. \& Abbasi, D.A. (2017). Potential Sources of Financing for Small and Medium Enterprises (SMEs) and Role of Government in Supporting SMEs. Journal of Small Business and Entrepreneurship Development 5(2): 39-47.

Adigun, A. (2016). To Investigate the Influencing Factors for Sustainable Packaging in a Multinational SME Supply Chain. University of Salford.

Ahmad Zaki, I. 2011. Formula usahawan berjaya. Edisi ke-1. Utusan Publications \& Distributors Sdn Bhd.

Ajzen, I. (1991). The theory of planned behavior. Organizational Behavior and Human Decision Processes 50(2): 179-211.

Alhosseini, S.S.N., Danai, H. \& Kamrani, M.N. (2015). Impact of Innovation Variables on Quality of Pharmaceutical Products Packaging. Journal of Applied Packaging Research 7(3): 1-22.

Andersson, U., Dasí, À., Mudambi, R. \& Pedersen, T. (2016). Technology, innovation and knowledge: The importance of ideas and international connectivity. Journal of World Business 51: 153-162.

Anon. (2018a). Pasar raya diminta beri ruang PKS jual produk. Berita Harian, 6. Putrajaya.

Anon. 2018b). Jaga kualiti produk. Harian Metro.

Anon. (2018c). Pembungkusan produk tarik pelanggan. Sinar Harian (Melaka dan Negeri Sembilan), 48. Seremban.

Azilahwati, A., Jessnor Elmy, M.J. \& Sariyah, A. (2016). The Measurement Model of Acceptance and Use of Social Commerce Among Small Medium-Sized Enterprises in Malaysia. Journal of Global Business \& Social Entrepreneurship (GBSE) 7(2): 130-140. 
Bettels, J., Haase, J. \& Wiedmann, K.P. (2020). Shaping consumer perception: effects of vertical and horizontal packaging alignment. Journal of Consumer Marketing. https://doi.org/10.1108/JCM05-2019-3231.

Chapman, P., James-Moore, M., Szczygiel, M. \& Thompson, D. (2000). Building Internet capabilities in SMEs. Logistics Information Management 13(6): 353-361.

Chittithaworn, C., Islam, A., Keawchana, T. \& Yusuf, D.H.M. (2011). Factors affecting business success of small \& medium enterprises (SMEs) in Thailand. Asian Social Science 7(5): 180-190.

Dial, L.A. \& Musher-Eizenman, D.R. (2020). Power of packaging: Evaluations of packaged fruits and vegetables by school-age children in the U.S. Appetite 148(104591).

Diana-Rose, F., Zariyawati, M.A., Norazlina, K., Annuar, M.A. \& Manisah, O. (2016). Consumers' Purchasing Decision towards Food Products of Small and Medium Enterprises. International Review of Management and Marketing 6(4): 836-842.

Felipe, F. de L. \& Márcia, R.N.G. (2018). The influence of the specifics of small businesses on innovation. Revista de Gestão 25(3): 242-257.

Hair, J., Money, A., Page, M. \& Samouel, P. (2007). Research Methods for Business. United States of America: John Wiley \& Sons, Ltd.

Handayani, E., Santi Dewi, I.G., Purnomo, W. \& Phitaloka, A.E. (2018). The Legality of food packaging to the production of small and medium enterprises (SME). IOP Conference Series: Earth and Environmental Science $175012191 \mathrm{hlm} .1-8$. IOP Publishing.

Hutahayan, B. \& Yufra, S. (2019). Innovation speed and competitiveness of food small and mediumsized enterprises (SME) in Malang, Indonesia: Creative destruction as the mediation. Journal of Science and Technology Policy Management 10(5): 1152-1173.

Hyder, S. \& Lussier, R.N. (2016). Why businesses succeed or fail: a study on small businesses in Pakistan. Journal of Entrepreneurship in Emerging Economies 8(1): 82-100.

Khan, G., Khan, F., Khan, G. \& Khan, F. (2017). The role of packaging and labelling in determining "halalness": an exploratory study of Muslims in two countries. International Journal Islamic Marketing and Branding 2(2): 85-99.

Lo, S.C., Tung, J. \& Huang, K.P. (2017). Customer Perception and Preference on Product Packaging. International Journal of Organizational Innovation 9(3): 3-15.

Mahani, A. \& Suraiya, I. (2019). Faktor PSiKKIT: Pendorong inovasi pembungkusan dalam kalangan Industri Kecil dan Sederhana berasaskan perusahaan makanan. Malaysian Journal of Society and Space 15(3): 1-14.

Mahani, A. \& Suraiya, I. (2020). The Relationship Between PSiKKIT Factors and Packaging Innovation Behavior: A Survey Among Micro-Food Entrepreneurs. Malaysian Journal of Social Sciences and Humanities 5(3): 1-12.

Mohamed, N.B.A., Medina, I.G. \& Romo, Z.G. (2018). The effect of cosmetics packaging design on consumers' purchase decisions. Indian Journal of Marketing 48(12): 50-61.

Mohd Nor Hakimin, Y., Fakhrul Anwar, Z. \& Hasannuddin, H. (2018). Entrepreneurial Orientation and Usage of External Business Support for SMEs. International Journal of Academic Research in Business and Social Sciences 8(1): 1-11.

Mohd Shaladdin, M., Wan Abdul Aziz, W.M.A. \& Muhammad Abi Sofian, A.H. (2011). Usahawan Kraf di Malaysia: Analisa Laluan Terhadap Perhubungan Inovasi Produk, Komitmen Perniagaan dan Perkembangan Perniagaan. Prosiding Persidangan Kebangsaan Ekonomi Malaysia ke VI (PERKEM VI), Ekonomi Berpendapatan Tinggi: Transformasi ke Arah Peningkatan Inovasi, Produktiviti dan Kualiti Hidup, 5-7 Jun 2011 Vol. 2, hlm. 208-217. Melaka.

Mohebbi, B. (2014). The art of packaging: An investigation into the role of color in packaging, marketing, and branding. International Journal of Organizational Leadership 3(2): 92-102.

Noorazah, M.N. \& Juhana, S. (2013). Model perkongsian pengetahuan dalam organisasi sektor swasta di Malaysia dan hubungannya dengan inovasi dan prestasi organisasi. Jurnal Teknologi (Sciences and Engineering) 64(1): 67-76.

Noorsafiza, M.S. (2016). Pembelajaran di organisasi dan persekitaran kerja terhadap pembentukan tingkah laku kerja inovatif: Kajian perusahaan kecil dan sederhana di Wilayah Ekonomi Pantai Timur, Malaysia. Tesis Dr.Fal. Universiti Kebangsaan Malaysia.

Nor Asiah, O., Hasnan, M.A. \& Muhamad Azrin, N. (2016). The effect of entrepreneurial orientation, innovation capability and knowledge creation on firm performance: A perspective on small scale entrepreneurs. Jurnal Pengurusan 48(2016): 187-200. 
Nor Ghani, M.N., Abul Bashar, B., Jamaliah, S. \& Syed, S.A. (2016). Innovation Barriers and Risks for Food Processing SMEs in Malaysia: A Logistic Regression Analysis. Malaysian Journal of Society and Space 12(2): 167-178.

Norkisme, Z.A., Nur Riza, M.S. \& Zainol, M. (2017). Faktor utama keupayaan inovasi syarikat milik rakyat Malaysia: Analisis kepentingan-keberkesanan hadapan pesaing perniagaan. Jurnal Pengukuran Kualiti dan Analisis 13(1): 35-54.

OECD. (2019). OECD SME and Entrepreneurship Outlook 2019. Paris.

Olcay, G.A. \& Bulu, M. (2015). Who should really get government support: an analysis of Turkish SME cases. International Journal of Knowledge-Based Development 6(1):34.

Ombi, N., Ambad, S.N.A. \& Bujang, I. (2018). The Effect of Business Development Services on Small Medium Enterprises (SMEs) Performance. International Journal of Academic Research in Business and Social Sciences 8(3): 117-130.

Pham, T.T.T. \& Matsunaga, N. (2019). Product and Process Innovation of Micro, Small and Medium Manufacturing Enterprises in Vietnam. Dlm. Matsunaga, N. (pnyt). Innovation in Developing Countries.Kobe University Monograph Series in Social Science Research hlm. 23-51. Singapore: Springer, Singapore.

Phuangrod, K., Lerkiatbundit, S. \& Aujiraponpan, S. (2017). Factor affecting innovativeness of small and medium enterprises in the five southern border provinces. Kasetsart Journal of Social Sciences 38(3): 204-211.

Polyakova, K. (2013). Packaging Design as a Marketing Tool and Desire to Purchase. Saimaa University of Applied Science.

Powell, J. (2012). The university role in the innovative leadership of small to medium sized enterprises. International Journal of Entrepreneurial Behavior \& Research 18(4): 396-416.

Rossi, M. \& Siggia, D. (2015). The financial choices of SMEs. The main problems of Italian agrofood firms' access to finance. Dlm. Vrontis, D., Weber, Y. \& Tsoukatos, E. (pnyt), Innovation, Entrepreneurship And Sustainable Value Chain In A Dynamic Environment hlm. 1877-1886. Euromed Press.

Rundh, B. (2016). The role of packaging within marketing and value creation. British Food Journal 118(10): 2491-2511.

Shahrin, N., Rahman, R., Zainol, N., Salmi, N.S. \& Wahab, M.F.A. (2016). Making It Green: The Food Packaging Perceptions And Practices Of Young Consumers. Malaysian Journal of Sustainable Environment 1(02): 28-38.

Sharina, S., Zaiha, Z., Mohamad, Y., Nizam, M., Nizat, M., Rozhan, A.D. \& Rohani, C.A. (2013). Khidmat nasihat teknikal MARDI bantu pembangunan PKS. Economic and Technology Management Review 8: 153-163.

Suraiya, I., Abd Hair, A., Mohd Yusof, H., Ahmad Raflis, C.O., Sarmila, M.S., Suhana, S., Zaimah, R. \& Azima, A.M. (2015). Penelitian tingkah laku inovasi firma makanan halal kecil di Malaysia: Satu analisis tentatif. GEOGRAFIA OnlineTM Malaysian Journal of Society and Space 11(2): 64-76.

Suwardi Afandi, A. \& Mohd Arif, W. (2014). Persepsi pengeluar snek terhadap pembungkusan dan pelabelan. Economic and Technology Management Review 9b: 155-162.

Suwardi Afandi, A., Mohd Yunus, S., Yaseer Suhaimi, M. \& Tapsir, S. 2016. Technology adoption decision among food manufacturers: What are the critical factors? Economic and Technology Management Review 11b: 75-85.

Ueasangkomsate, P. \& Jangkot, A. (2019). Enhancing the innovation of small and medium enterprises in food manufacturing through Triple Helix Agents. Kasetsart Journal of Social Sciences 40(2): 389-394.

Vasilescu, L. (2014). Accessing Finance for Innovative Eu Smes - Key Drivers and Challenges. Economic Review: Journal of Economics \& Business 12(2): 35-47.

Vivine, T.A. (2018). Kepentingan Pembungkusan Produk Dalam Pemasaran. Sinar Harian Online.

Yahaya, J., Ibrahim, S., A.H. (2018). Model Kesediaan Pelaksanaan Teknologi Maklumat untuk Perusahaan Kecil dan Sederhana Ke Arah Era Revolusi Industri 4.0. Ejournals.Ukm.My 54

Zaini, M., Zaimah, D. \& Hasnah, A. (2004). Teknologi dan Kemahiran dalam Industri Skala Kecil. Dlm. Rahmah, I. (pnyt). Industri Kecil Malaysia:Isu Pembiayaan, Teknologi dan Pemasaran hlm. 67-95. Bangi, Selangor: Penerbit UKM. 